\title{
Melanoma involving the surgical scar following surgery and craniospinal irradiation for childhood medulloblastoma: case report and literature review
}

\author{
Daniel J. Tandberg ${ }^{1}$, Gregory W. Osmond ${ }^{2}$, Brian G. Czito ${ }^{* 1}$ \\ ${ }^{1}$ Department of Radiation Oncology, Duke University School of Medicine, Durham, NC 27710, United States \\ ${ }^{2}$ Department of Pathology, Duke University School of Medicine, Durham, NC 27710, United States
}

Received: November 11, 2015

Accepted: December 8, 2015

Online Published: December 22, 2015

DOI: $10.5430 /$ crcp.v3n1p43

URL: http://dx.doi.org/10.5430/crcp.v3n1p43

\begin{abstract}
Patients with childhood cancer are at increased risk of developing melanoma as a secondary malignancy. It is unclear whether this risk is related to underlying patient predisposition or secondary to treatment effect. We report a case of a 43-year-old male with a history of childhood medulloblastoma at the age of 13 treated with surgery and craniospinal irradiation who presented with an enlarging occipital mass and contiguous, cutaneous, ulcerated nodule. The nodule appeared to arise within the patient's occipital surgical scar. Imaging revealed a large mass in the posterior neck soft tissues with associated lytic destruction of the occiput and $\mathrm{C} 1$ vertebrae. Biopsy was consistent with melanoma, epitheliod and small cell types. No other sites of disease or cutaneous lesions were identified. Despite aggressive therapy with radiation therapy and chemotherapy, the lesion progressed and the patient died of complications of obstructive hydrocephalus. It is hypothesized that this patient developed melanoma as a result of his radiation therapy exposure or that tumor arose de novo in the surgical scar tissue. The presentation of the melanoma in this case and the potential etiologies are unique.
\end{abstract}

Key Words: Medulloblastoma, Melanoma, Neoplasms, Radiation induced, Second primary

\section{INTRODUCTION}

Survivors of childhood cancer are at increased risk of secondary malignancies including malignant melanoma. ${ }^{[1,2]}$ It is not clear if this increased risk is related to underlying patient susceptibilities or as an adverse effect of cancer therapy. We report the case of a patient with prior history of medulloblastoma that developed an invasive melanoma within his healed medulloblastoma surgical scar. We discuss potential etiologies of the melanoma in this case including radiation induction and scar tissue.

\section{CASE REPORT}

A 43-year-old male presented with a five month history of occipital headaches and enlarging nuchal mass. His past medical history was significant for medulloblastoma at age 13, undergoing gross total resection through occipital craniotomy followed by radiation therapy ( 30 Gy to the craniospinal axis and 20 Gy cranial boost). Physical examination revealed patchy alopecia and a healed posterior midline scar extending from the occiput to mid cervical area. A $2 \mathrm{~cm} \times 1 \mathrm{~cm}$ ulcerated nodule was present at the superior aspect of the scar (see Figure 1) with a moderately tender $8 \mathrm{~cm} \times 8 \mathrm{~cm}$

*Correspondence: Brian G. Czito; Email: brian.czito@dm.duke.edu; Address: Department of Radiation Oncology, Duke University School of Medicine, DUMC Box 3085, Durham, NC 27710, United States. 
soft tissue mass palpable in the posterior neck deep to the scar, extending from the occiput to approximately $\mathrm{C} 4$.

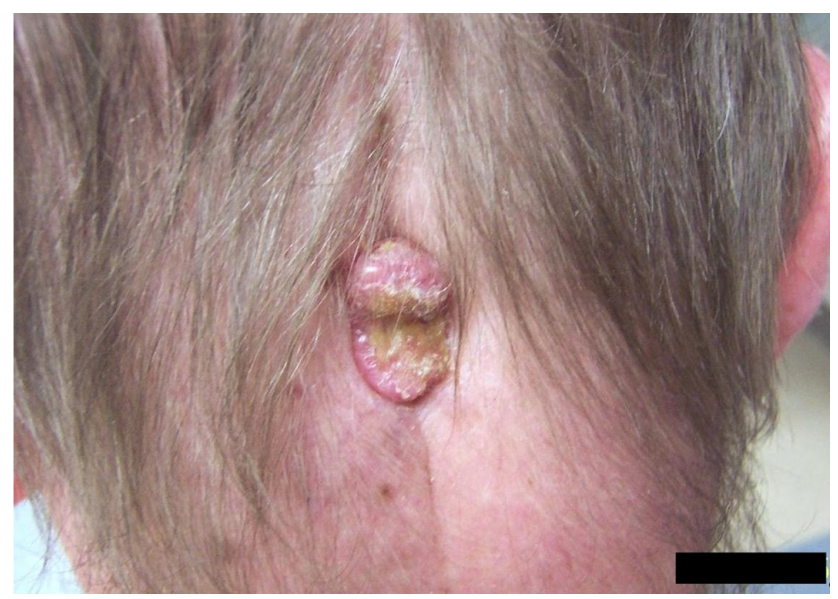

Figure 1. Photograph of ulcerated nodule present at the superior aspect of the patient's surgical scar from prior medulloblastoma resection

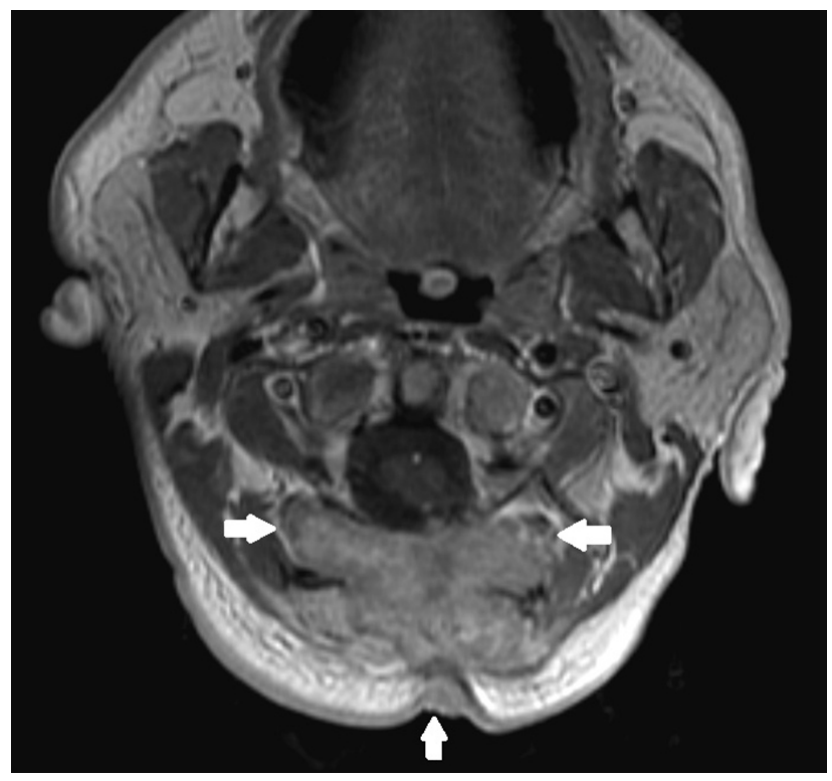

Figure 2. Axial T1 weighted MRI demonstrates a mass $(3.5 \mathrm{~cm} \times 5.8 \mathrm{~cm} \times 7.2 \mathrm{~cm})$ at the craniocervical junction with its epicenter in the posterior soft tissues of the neck. Lytic destruction of the occiput and posterior arch of $\mathrm{C} 1$ are noted as well as peripheral extension to the skin surface.

MRI revealed a large mass $(3.5 \mathrm{~cm} \times 5.8 \mathrm{~cm} \times 7.2 \mathrm{~cm})$ at the craniocervical junction with its epicenter in the posterior soft tissues of the neck (see Figure 2). Lytic destruction of the occiput and posterior arch of $\mathrm{C} 1$ were noted, as well as contiguity with the posterior spinal cord at $\mathrm{C} 2$ with peripheral extension to the skin surface. Biopsy demonstrated a diffusely infiltrative population of large, pleomorphic cells with nuclear pseudoinclusions and readily identifiable mitoses (see Figure 3). Both epithelioid and small cell morphologies were seen. Immunohistochemical staining demonstrated the malignant cells were strongly positive for S100 (see Figure 4) and HMB45, consistent with melanocytic differentiation. A diagnosis of melanoma, epitheliod and small cell types, was rendered. BRAF mutation testing was not performed. Disease outside of the previously described neck mass was not identified by PET scan. He was not felt to be a candidate for resection, and was thus evaluated for palliative therapy.

The patient was treated with a course of external beam radiation therapy using an intensity-modulated technique to a total of 50.4 Gy at $1.8 \mathrm{~Gy}$ per fraction. Restaging PET scan one month following treatment completion revealed a moderate decrease in FDG activity with no evidence of additional disease. Clinical regression of his cutaneous lesion was noted as was mild regression of the underlying soft tissue mass.

Prior to initiating systemic therapy, follow-up clinical examination revealed clear progression of the cutaneous lesion. He was treated with temozolomide with repeat PET showing essentially stable findings. He subsequently received dacarbazine; however, three weeks later he developed progressive difficulty with ambulation, nausea, vomiting, and confusion. MRI revealed obstructive hydrocephalus due to progressive disease. After patient and family discussion, it was decided to proceed with comfort measures only. The patient expired approximately one week following hospital discharge.

\section{Discussion}

Advances in the multi-modality treatment of childhood malignancies have resulted in improved long-term outcomes. ${ }^{[3]}$ However, with increased survival there is heightened awareness of delayed cancer development and treatment related morbidity, including secondary malignancies. In this report we describe a patient who developed melanoma as a second malignancy thirty years following treatment of childhood medulloblastoma.

Several large studies have evaluated the incidence of secondary malignancies in survivors of childhood malignancies. In the Childhood Cancer Survivor Study Cohort, the cumulative thirty year incidence of secondary malignancies was $7.9 \%$ among 5-year survivors of childhood cancer. ${ }^{[2]}$ Risk factors for the development of secondary malignancies included female sex, older age at diagnosis, earlier treatment era, diagnosis of Hodgkin lymphoma, and treatment with radiation therapy. For children with CNS tumors specifically, the rate of secondary malignancies was $4.5 \%$ at 25 years from diagnosis. ${ }^{[4]}$ CNS tumors (most commonly gliomas), soft-tissue sarcomas, and thyroid cancers were the most com- 
monly reported second malignancies in this population.

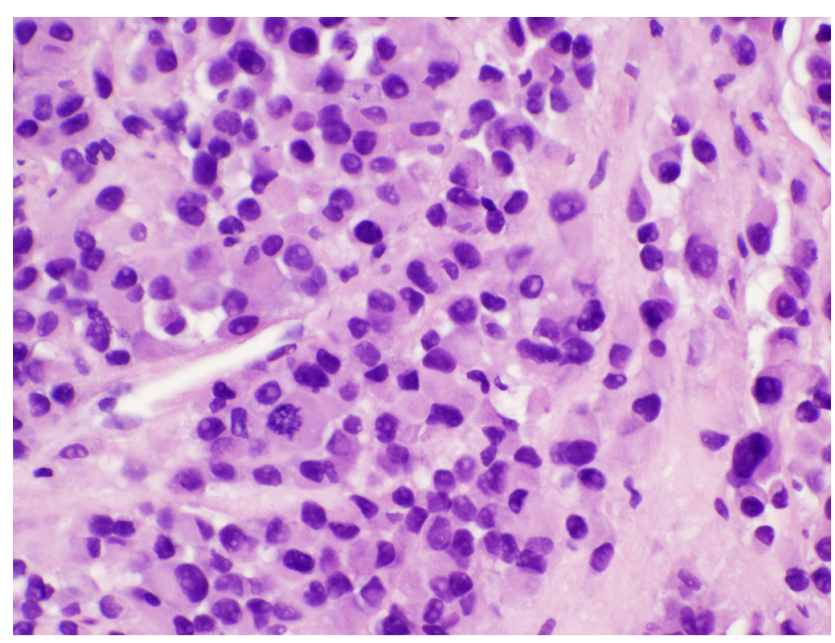

Figure 3. Hematoxylin and eosin stain from biopsy of cutaneous lesion demonstrates a diffusely infiltrative population of large, pleomorphic cells with nuclear pseudoinclusions and readily identifiable mitoses $(40 \times)$

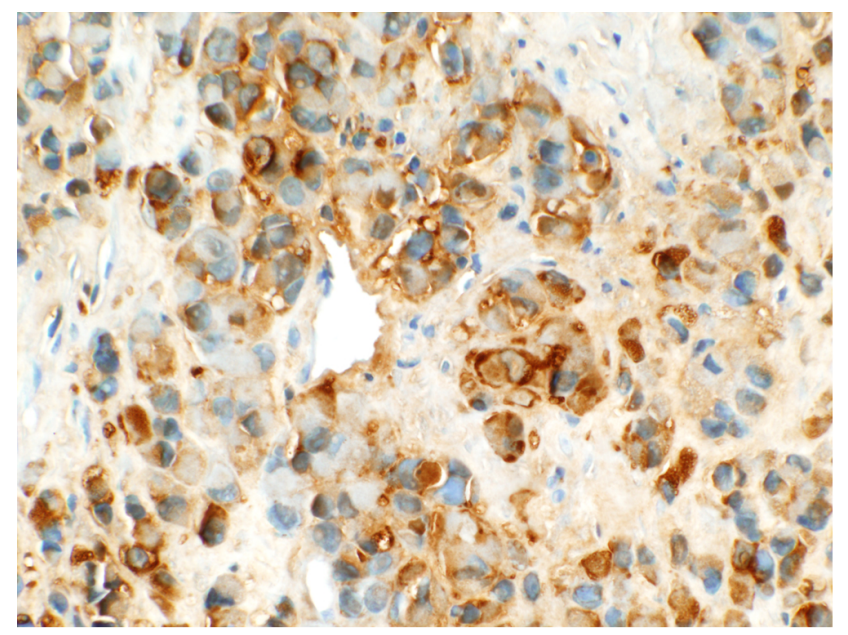

Figure 4. Immunohistochemical staining for S100, strongly positive $(40 \times)$

Melanoma as a secondary malignancy following childhood cancer is uncommon. In a systematic review including 151,575 childhood cancer survivors, $212(0.14 \%)$ children were reported to develop melanoma as a secondary malignancy, with an overall incidence of $5.3 \%$ of all secondary tumors. ${ }^{[1]}$ In the Childhood Cancer Survivor Study cohort $(n=14,359), 48$ melanomas were observed as secondary malignancies with a median time to occurrence of 18.9 years. ${ }^{[2]}$ The incidence of melanoma in this population was 3.3-fold that expected in the general population.

In this case, the location of the melanoma within the prior radiation field and long latency period suggest the melanoma

Published by Sciedu Press was induced by radiation exposure. Radiation therapy has been shown to be a risk factor for the development of second malignancies in childhood cancer survivors. ${ }^{[3]}$ It is unclear, however, whether radiotherapy is a risk factor for the development of melanoma as a secondary malignancy. In a small case-control study, radiotherapy was shown to be marginally associated with the development of melanoma as a secondary malignancy (HR 1.07 per additional Gy at doses $>15 \mathrm{~Gy}$ ). ${ }^{[5]}$ Using cancer registry data, another study reported 8 malignant melanomas in patients receiving radiation therapy for childhood cancer, compared to 3.1 expected cases. ${ }^{[6]}$ However, 13 cases of melanoma were reported in patients not receiving radiation therapy, suggesting a radiation-independent underlying predisposition.

Reports of melanoma arising within the radiation field following cranial irradiation are especially rare. Corpon et al. identified 11 patients with melanoma presenting as a secondary malignancy following childhood cancer, 2 of which were scalp melanomas arising within a radiation field. ${ }^{[7]} \mathrm{Sev}$ eral large reports of children with childhood cancer treated with cranial irradiation do not report any cases of melanoma arising within radiation fields. ${ }^{[8-10]}$ In one report of 1,262 primary medulloblastoma patients, 20 developed a secondary malignancy, one of which was a melanoma arising outside the radiation field. ${ }^{[8]}$

Alternatively (or concurrently with a radiation dependent mechanism), the pathogenesis of the melanoma could be related to surgical trauma and associated scar tissue. As described, this tumor appeared to arise within the occipital scar tissue from the patient's occipital craniotomy. Skin cancers arising in burn scar tissue are rare but well reported in the literature. ${ }^{[11,12]}$ In a review of the English literature, KowalVern and Criswell identified 412 reported cases of burn scar neoplasms, $6 \%$ of which $(n=23)$ were melanomas. ${ }^{[13]}$ The mean latency period from the time of the burn to appearance of melanoma in the burn site was 41 years. Skin cancers arising specifically in surgical scar tissue, as in this case, are less frequently reported. Epidermoid, squamous cell carcinomas, and basal cell carcinomas have all been reported to arise from surgical scars. ${ }^{[14,15]}$ However, to our knowledge, there appears to be only one reported case of a melanoma arising in a surgical scar. In that report a 41 year old female developed melanoma in a four year old cesarean section scar while pregnant. ${ }^{[16]}$ Several theories have been proposed to describe the pathogenesis of neoplasms arising within scar tissue, including chronic inflammation and irritation, release of tissue toxins, and a lack of immunological mechanisms in scars to restrict tumor growth. ${ }^{[13]}$

In conclusion, we present a rare case of melanoma arising 
within the surgical scar and radiation field of a childhood survivor of medulloblastoma. The location of this tumor within the occiput as well as locoregionally aggressive nature of this tumor is unusual. While it is possible this represented metastatic melanoma from an unknown primary, it seems more likely this represented locally advanced primary disease. Further, the pathogenesis of this tumor appears unique.
It may be hypothesized that this patient developed melanoma as a result of prior radiation therapy exposure or that this tumor arose in the surgical scar tissue independent of radiation induction. It is similarly possible that sun exposure in the setting of alopecia secondary to radiation therapy further increased his risk of developing melanoma within the treatment field.

\section{REFERENCES}

[1] Braam KI, Overbeek A, Kaspers GJL, et al. Malignant melanoma as second malignant neoplasm in long-term childhood cancer survivors: A systematic review. Pediatric Blood \& Cancer. 2012; 58: 665-74. PMid: 22232079. http://dx.doi.org/10.1002/pbc. 24023

[2] Friedman DL, Whitton J, Leisenring W, et al. Subsequent neoplasms in 5-year survivors of childhood cancer: the Childhood Cancer Survivor Study. J Natl Cancer Inst. 2010; 102: 1083-95. PMid: 20634481. http://dx.doi.org/10.1093/jnci/djq238

[3] Howlader NNA, Krapcho M, Neyman N, et al. SEER Cancer Statistics Review, 1975-2009. In. Bethesda, MD: National Cancer Institute.

[4] Armstrong GT, Liu Q, Yasui Y, et al. Long-term outcomes among adult survivors of childhood central nervous system malignancies in the Childhood Cancer Survivor Study. J Natl Cancer Inst. 2009; 101: 946-58. http://dx.doi.org/10.1093/jnci/djp148

[5] Guerin S, Dupuy A, Anderson H, et al. Radiation dose as a risk factor for malignant melanoma following childhood cancer. European Journal of Cancer. 2003; 39: 2379-86. http: //dx.doi.org/10.1016 /S0959-8049(03)00663-4

[6] Inskip PD, Curtis RE. New malignancies following childhood cancer in the United States, 1973-2002. International Journal of Cancer. 2007; 121: 2233-40. PMid: 17557301. http://dx.doi.org/10. 1002/ijc. 22827

[7] Corpron CA, Black CT, Ross MI, et al. Melanoma as a second malignant neoplasm after childhood cancer. American Journal of Surgery. 1996; 172: 459-62. http://dx.doi.org/10.1016/S0002-961 0 (96) 00221-8

[8] Goldstein AM, Yuen J, Tucker MA. Second cancers after medulloblastoma: population-based results from the United States and
Sweden. Cancer Causes \& Control. 1997; 8: 865-71. PMid: 9427429. http://dx.doi.org/10.1023/A : 1018464328836

[9] Kimball Dalton VM, Gelber RD, Li F, et al. Second malignancies in patients treated for childhood acute lymphoblastic leukemia. J Clin Oncol. 1998; 16: 2848-53. PMid: 9704738.

[10] Büyükpamukçu M, Varan A, Yazici N, et al. Second malignant neoplasms following the treatment of brain tumors in children. J Child Neurol. 2006; 21: 433-6. PMid: 16901454.

[11] Atzeni M, Serratore F, Zaccheddu F, et al. Multiple melanoma arising on a burn scar and extensive sunburn: a case report and a review of the literature. Melanoma Res. 2009; 19: 195-8. PMid: 19543127. http://dx.doi.org/10.1097/CMR.0b013e32832ccd3f

[12] Kikuchi H, Nishida T, Kurokawa M, et al. Three cases of malignant melanoma arising on burn scars. J Dermatol. 2003; 30: 617-24. PMid: 12928532. http://dx.doi.org/10.1111/j.1346-8138. 2003.tb00445.x

[13] Kowal-Vern A, Criswell BK. Burn scar neoplasms: a literature review and statistical analysis. Burns. 2005; 31: 403-13. PMid: 15896501. http://dx.doi.org/10.1016/j.burns. 2005.02.015

[14] Korula R, Hughes CF. Squamous cell carcinoma arising in a sternotomy scar. Ann Thorac Surg. 1991; 51: 667-9. http://dx.doi . org/10.1016/0003-4975 (91) 90337-P

[15] Ozyazgan I, Kontaçs O. Basal cell carcinoma arising from surgical scars: a case and review of the literature. Dermatol Surg. 1999; 25: 965-8. PMid: 10594632. http://dx.doi.org/10.1046/j.152 4-4725.1999.99192.x

[16] Brandt JS, Fishman S, Magro CM. Cutaneous melanoma arising from a cesarean delivery skin scar. J Perinatol. 2012; 32: 807-9. PMid: 23014385. http://dx.doi.org/10.1038/jp. 2011.172 